\title{
Numerical Investigation of Influential Parameters Concerning the Experimental Testing of RC Frames Under Cyclic Loading
}

\author{
E. Kirtas* and D.J. Kakaletsis
}

\begin{abstract}
Department of Civil Engineering, Surveying Engineering and Geomatics, Technological Educational Institution of Central Macedonia, Serres, Greece
\end{abstract}

\begin{abstract}
Numerical simulations have been widely used to study the inelastic response of reinforced concrete structures under earthquake loading. Yet, due to the complex nature of structural inelastic behavior, experimental results are often required to verify the efficiency of applied numerical schemes. In this paper, experimental results of bare reinforced concrete frame models are employed to validate numerical calculations using the code Seismostruct. Moreover, numerical simulations investigate the influential parameters related to the physical experiment configuration and numerical analysis options and determine their effect on the obtained structural response. The experimental setup concerns a well-defined case study of a reinforced concrete frame under cyclic horizontal loading. The fixed base frame is subjected to increasing horizontal forces, leading to the development of plastic hinges at the structural elements. The adopted numerical approach describes successfully the inelastic behavior of the frame, as indicated by the obtained results of the overall structural response as well as the plastic hinge formation at cross section level. Comparison of the plastic hinge formation mechanism in particular, raises interesting remarks on the conditions and constraints of the physical experiments and highlights the valuable contribution of numerical simulations in their design.
\end{abstract}

Keywords: Fiber analysis, distributed plasticity, influential parameters, numerical simulations, physical experiments, plastic hinges, RC frames.

\section{INTRODUCTION}

Numerical simulations are widely used in everyday civil engineering practice to design safe and cost-efficient structural systems. Moreover, numerical analysis is a valuable tool for academic purposes, to advance scientific knowledge in many particular scientific fields with demanding requirements in terms of problem complexity and computational cost. The use of numerical methods to investigate the inelastic response of reinforced concrete (RC) structures under earthquake loading is such an example. Nowadays, considering the current trend in modern Seismic Codes for simplified inelastic analysis even in the case of common structures (e.g. calculation of behavior factor q in Eurocode 8), it is imperative to provide efficient and reliable numerical procedures.

Despite the large number of available numerical codes, the complicated nature of the inelastic response of RC structures often raises questions regarding the efficiency of numerical analysis approaches in many cases. Several parameters, including the material and cross-section behavior under cyclic quasi-static or dynamic loading, the application of seismic forces etc, present a complicated problem with many uncertainties. Experimental results are therefore required, to verify the efficiency and applicability of numerical analysis in the examined cases. To this end, validation of numerical simulations using physical experiments is very important in

*Address correspondence to this author at the Department of Civil Engineering, Surveying Engineering and Geomatics, Technological Educational Institution of Central Macedonia, GR-62124 Serres, Greece;

Tel: +30 23210 49323; E-mail: kirtas@teiser.gr terms of providing confidence on the obtained analysis results. Such validation procedures have been applied in a wide variety of engineering problems, ranging from bare and infilled reinforced concrete frames under cyclic seismic-type loading [1-6] to complex system behavior including soilstructure interaction phenomena in centrifuge and shaking table facilities [7-9]. For academic research purposes, the use of calibrated numerical schemes offers the possibility to explore a large number of slightly different problem configurations with a high degree of certainty and without the cost of the physical experiment itself.

In the present paper, numerical code Seismostruct [10] is selected to investigate the inelastic response of bare RC frames under cyclic quasi-static loading that were experimentally tested by Kakaletsis [11]. Modeling of RC frame sections is achieved using the distributed plasticity fiber approach $[12,13]$ and the constitutive laws proposed by Mander et al. [14] for concrete and Menegotto and Pinto [15] for steel bars. A detailed presentation of the utilized models implementation is given in the following sections.

The purpose of the paper is twofold. First, numerical simulation of physical experiments is expected to shed light on several aspects of the inelastic response of the examined $\mathrm{RC}$ frames, especially those that are difficult to cover due to instrumentation limitations during testing. The task of reproducing the response observed at the employed physical experiments is even more challenging, since the size of the examined frame specimens is $1 / 3$ of the prototype scale, introducing additional constraints concerning the applicability of the selected numerical scheme. In this context, an exten- 
sive numerical procedure was implemented, investigating the effect of parameters concerning (a) the exact reproduction of the physical testing conditions and (b) the influence of options related to the specific numerical analysis code.

Second, the validated numerical scheme can be employed during present and future experimental efforts, as feedback to plan an efficient experimental program and achieve a proper configuration of the reinforced frame members. To this end, it is quite interesting to examine whether a blind prediction process, using slightly different parameter values and modeling approaches, is able to provide a range of analysis results that reproduce the main response aspects of the physical model in a satisfactory way.

\section{PHYSICAL EXPERIMENT}

\subsection{Description of Physical Experiment Setup}

The experimental program comprised of several models of bare and brick infilled single-story one-beam RC frames, with and without openings. The $1 / 3$ scale models configuration and cross-section detailing are presented in Fig. (1). The present paper focuses on the experimental investigation of bare frames and more specifically Specimen B with common stirrups as shear reinforcement and Specimen BS with rectangular spirals.

The geometric characteristics of the RC frames were the same for all specimens. The beam and the column cross sections were $100 \times 200 \mathrm{~mm}$ and $150 \times 150 \mathrm{~mm}$ respectively. The above dimensions correspond to one third (1/3) scale of the prototype frame sections, $300 \times 600 \mathrm{~mm}$ for the beam and $450 \times 450 \mathrm{~mm}$ for the columns. The close distance of stirrups throughout the entire column length is dictated from special detailing and confinement requirements of the Greek Reinforced Concrete Code EKOS 2000 [16], since the entire col- umn length is considered as critical region due to the lack of infill wall at one side. On the other hand, the critical regions at the beam, where shear reinforcement distance is smaller, are located at the two ends of the beam element. Each beamcolumn joint had five horizontal stirrups to prohibit brittle shear failure. The longitudinal reinforcement diameter $\varnothing 5.60 \mathrm{~mm}$ and stirrups diameter $\varnothing 3 \mathrm{~mm}$ of the frame members correspond to one third $(1 / 3)$ scale of $\varnothing 18 \mathrm{~mm}$ and $\varnothing 8 \mathrm{~mm}$ reinforcement diameters respectively of the prototype frame (the correlation refers to the dimension proportions of the reinforcement bars to the cross-section height and not to the actual reinforcement area in prototype scale).

At the specimens, low strength smooth steel bars were used, although the rule for the construction practice is to use high strength ribbed steel bars. The reason for this selection is due to the limited availability of the scaled diameters in the market. On the other hand, if ribbed reinforcement bars had been used during the experiment, the concrete-steel bond effect due to scaled model dimensions would have been significant, compared to the case of smooth bars were the concrete-steel interface resembles that of the prototype structure.

Material tests were conducted on concrete and reinforcing steel samples, to determine in detail the utilized material properties. The mean compressive strength of the frame concrete was $28.51 \mathrm{MPa}$ for cubic specimens. The yield stress of longitudinal and transverse steel was $390.47 \mathrm{MPa}$ and 212.2MPa respectively.

The reinforced concrete frame represented a typical ductile concrete construction, built in accordance with the currently used codes and standards in Greece, which are very similar to Eurocodes 2 and 8 [17, 18]. The average sum of the flexural capacity of the column to that of the beam was also confirmed by these standards. The ultimate bending moment $M_{u}$ for the column ends is calculated equal to
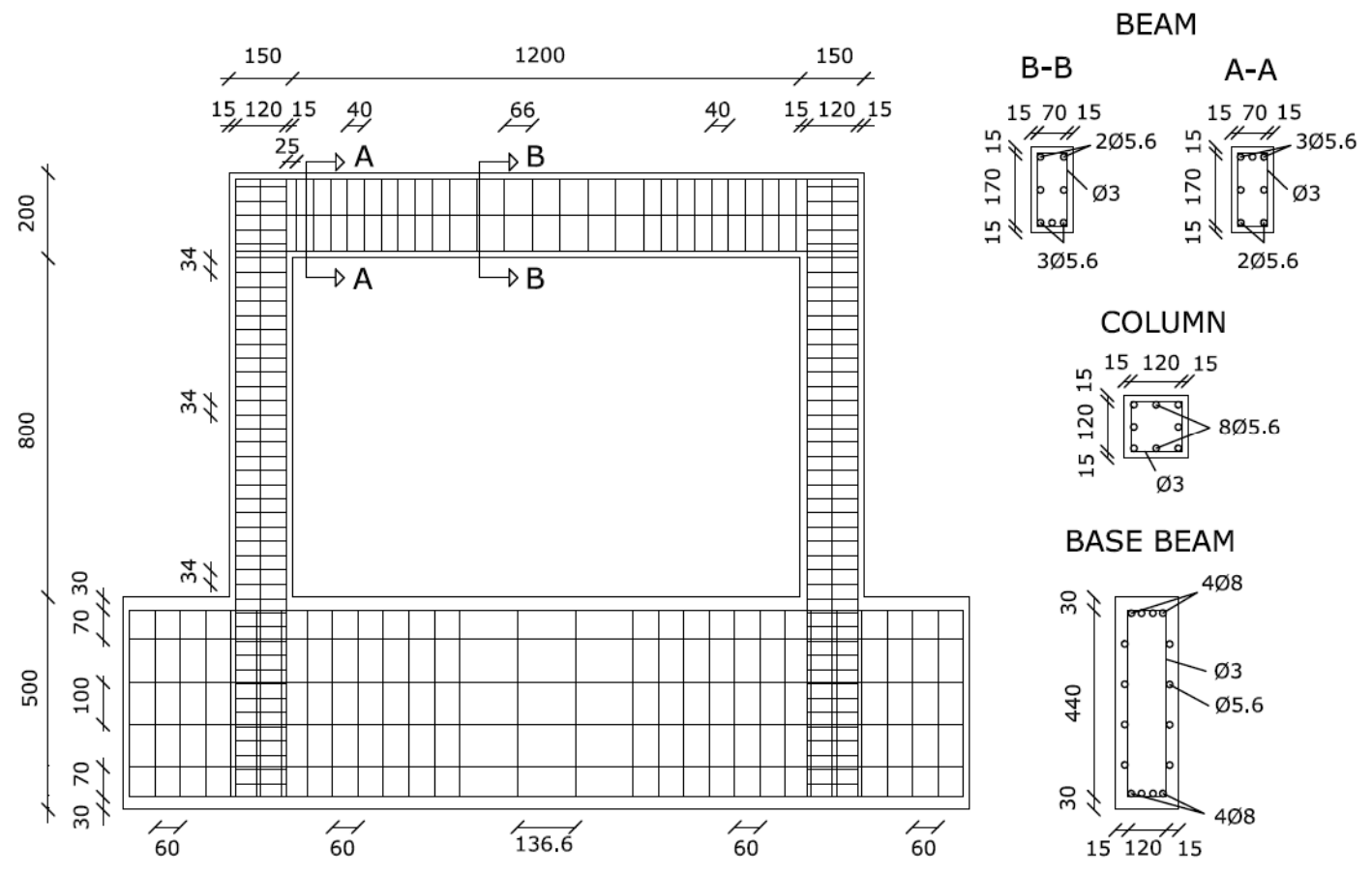

Fig. (1). Configuration and detailing of the examined $1 / 3$ scale $\mathrm{RC}$ frames (dimensions in $\mathrm{mm}$ ). 
$7.3 \mathrm{kNm}$, whereas for the beam the ultimate value is equal to $4.6 \mathrm{kNm}$ and $6.1 \mathrm{kNm}$ for the bottom and top edge respectively. Thus, for the beam-column connections examined in this investigation, the mean bending moment strength ratio approaches 1.40 , i.e. the value usually required by modern seismic regulations. The purpose of this design was to drive the formation of plastic hinge in the beams. It should be noted though that the minimum column/beam strength ratio is calculated equal to 1.20 , which may be well above unity yet is capable of allowing for partial plastic hinge formation at the column's end in case of substantial hardening branch of the inelastic response at the beam cross-section.

For the experimental testing of the described frame under earthquake loading, an arbitrarily selected quasi-static reversed cyclic lateral load and an axial compressive load per column were applied. The test setup is shown in Fig. (2). The lateral load was applied by means of a double action hydraulic actuator, using a configuration that imposes the load successively on one of the opposite beam-column joints, depending on the direction of the horizontal movement. The vertical loads were exerted by manually controlled hydraulic jacks that were tensioning four strands at the top of the column whose forces were maintained constant during each test. The level of this axial compressive load per column was set $50 \mathrm{kN}(10 \%$ of the ultimate). The axial force applied to the columns was considered to simulate the existing gravitational loading of the prototype frame as well as to prevent the columns from developing tension. One LVDT (linear variable differential transformer) measured the lateral drift of the frame and a load cell measured the lateral force of the hydraulic actuator. The loading program included full reversals of gradually increasing displacements. Two reversals were applied for each displacement level. The cycles started from a ductility level 0.8 corresponding to an amplitude of about $\pm 2 \mathrm{~mm}$ (the displacement of yield initiation to the system is considered as ductility level $\mu=1$ ) and were followed gradually by ductility levels $2,4,6,8,10,12$ corresponding approximately to amplitudes $6,12,18,24,30,36 \mathrm{~mm}$ (Fig. 3).

A more detailed presentation of the experimental program is given by Kakaletsis $[11,19]$. Several parts of the described experimental program have been already used to assist the classification of failure modes for infilled frames [20].

\subsection{General Remarks and Limitations of Experimental Setup}

Single-story single-bay frames, similar to the one presented in this study, are usually supposed to represent the base story of frame-type RC structures where the maximum cross-section force levels are observed during seismic response. There are several different ways to model physically the frame at the base of a multi-story structure. The most popular options would be:

(a) to model a single-story frame, representing the base of the multi-story prototype.

(b) to model a larger sub-assemblage that includes the ground floor frame, presuming of course that testing facility limitations allow for such a selection.

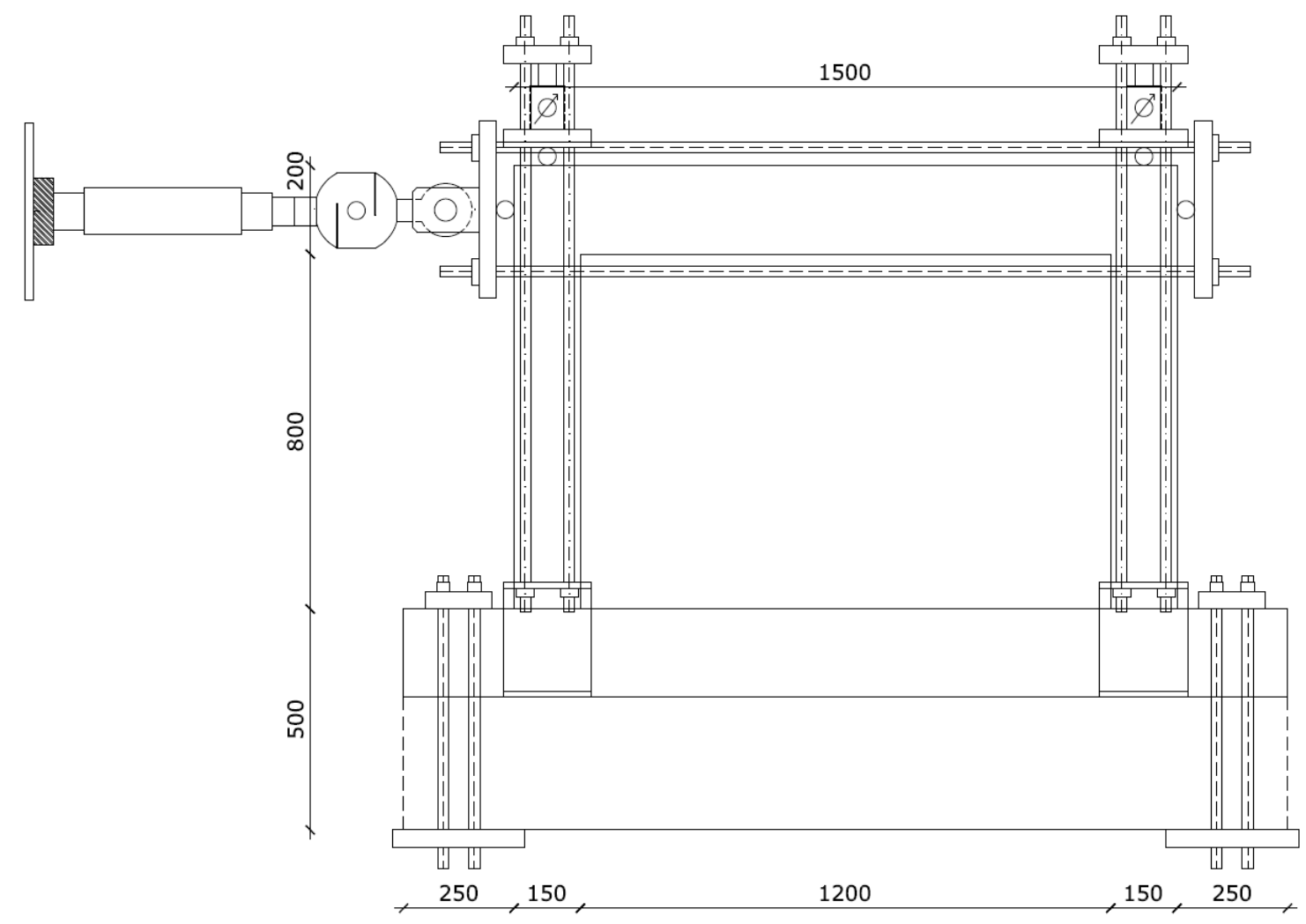

Fig. (2). Experimental setup to investigate the frame response under earthquake loading (dimensions in $\mathrm{mm}$ ). 
(c) to model the full multi-story structure, which requires a large testing facility or small scale physical models (probably both) and is not further discussed herein.

Option (a) is relatively cheap and easier to employ, yet several inherent features of the frame configuration result in deviation from the actual response of the base frame of a multi-story structure. The axial compressive forces of the columns, coming from the dead and live loads of the upper stories, can be applied using hydraulic jacks [21,22]. On the other hand, the actual bending moment at the top of the column as well as the beam-column joint rotation of the prototype multi-story structure, cannot be easily reproduced. Indeed, the rotation of the joint and the developing crosssection bending moments are also affected by the stiffness properties of the next-floor column, which is not present at the experimental model. To this end, the examined models aim in reproducing moment-free boundary conditions, using proper setup during the loading application, taking though into consideration the difference from the prototype structure.

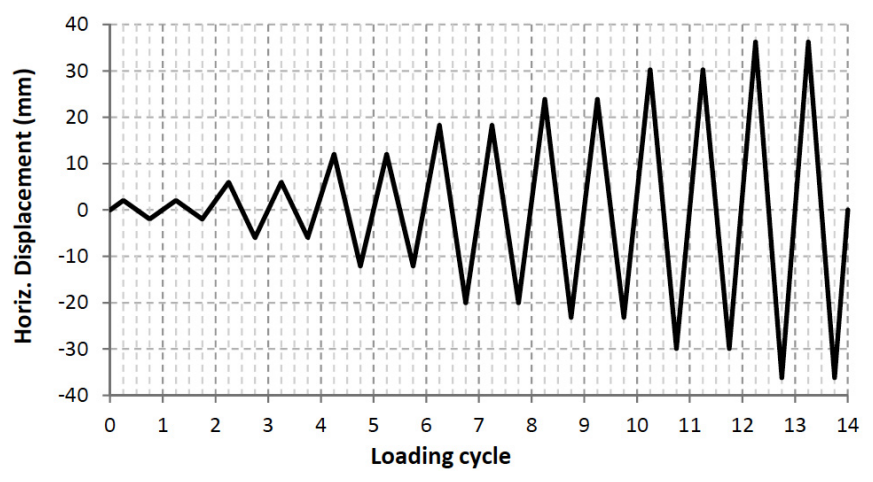

Fig. (3). Quasi-static cyclic earthquake loading program.
A selection of a larger sub-assemblage consisting of more than one stories (option b), overcomes the aforementioned disadvantage of the single-story frame models. In this case, external loading and boundary conditions are applied at points where zero developing moments or displacements are expected $[23,24]$. Yet, due to movement of the inflection points on structural elements during the experiment, the problem of reproducing boundary values during testing is expected to introduce some modeling error which must be tolerated [24]. Nevertheless, this model selection provides increased accuracy in the duplication of boundary conditions in panels located away from points of load application.

The selected single-story single-bay frame configuration investigated in the present study is intended to reproduce moment-free boundary conditions and avoid any undesirable boundary effects during testing at the points of load application. Indeed, both vertical and horizontal forces are applied using a roller configuration, as depicted in Figs. $(\mathbf{2}, \mathbf{4})$, to achieve zero externally applied parasitic forces or moments on the frame. Each load is applied on a steel plate that transfers, through the roller bearing, only a vertical-to-the-plate force on the beam-column joint. The roller implementation is supposed to ensure that no moments or forces parallel-to-theplate can be transferred on the joint. Nevertheless, the complex nature of the employed setup cannot guarantee without further investigation that conditions of pure roller behavior are established. Friction between the roller and the steel plates along with the application of large external vertical forces on the columns during the physical experiment, may induce slightly different behavior compared to the anticipated theoretical one.

A detailed examination of roller bearing behavior is presented by Lee et al. [25] in Fig. (5). The frictional resistance of the roller motion, which is substantially smaller compared to the sliding motion, is attributed to (a) relative sliding of the actual finite contact surface, (b) energy dissipation due to

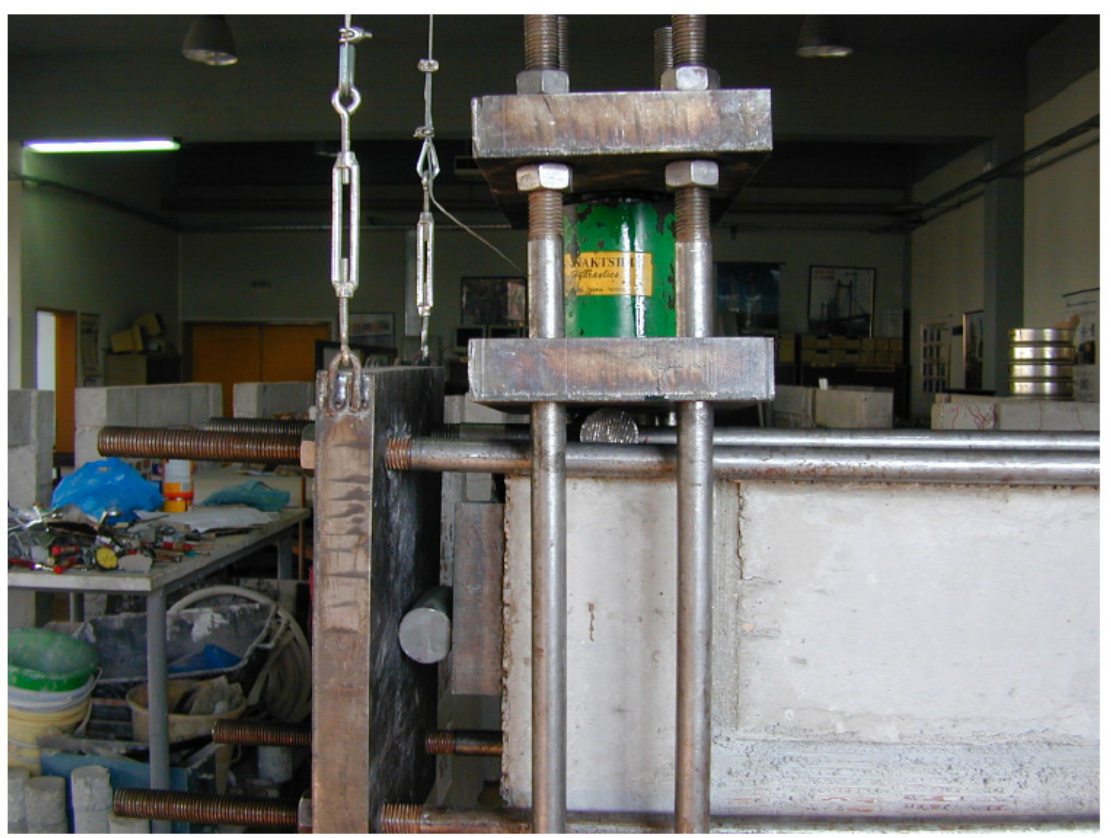

Fig. (4). Roller implementation for the application of the vertical and horizontal frame forces. 
internal friction, (c) surface imperfection resulting in contact taking place on asperities and (d) surface adhesion phenomena [26]. The roller friction coefficient is equal to $\mu_{\mathrm{r}}=\delta / \mathrm{R}$, where $\mathrm{R}$ is the roller radius and parameter $\delta$ has dimensions of length and depends on the contact material properties. Common $\delta$ values for steel-on-steel contact vary between 0.002 inches $(0.05 \mathrm{~mm})$ for rough surfaces to 0.0002 inches $(0.005 \mathrm{~mm})$ for hard-polished steel. Coefficient $\delta$ may increase with loading, especially when plastic deformations of the elements in contact are involved. For roller radius $\mathrm{R}=20 \mathrm{~mm}$, the aforementioned $\delta$ values yield a friction coefficient varying between $\mu_{\mathrm{r}}=0.00025$ and 0.0025 (depending on the material surface properties), which is considerably smaller compared to the sliding friction coefficient between steel surfaces that obtains values between $\mu_{\mathrm{s}}=0.10$ and 0.74 for greasy and dry conditions respectively.

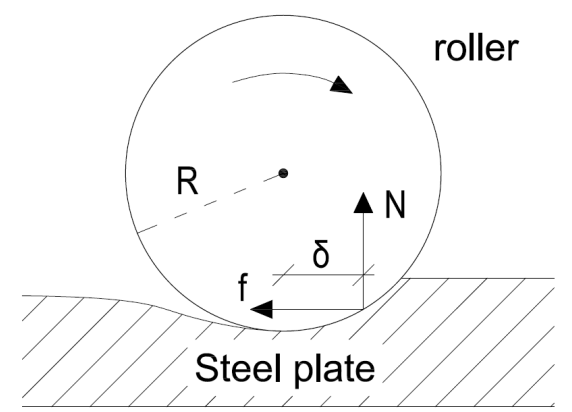

Fig. (5). Contact forces between a roller and a plate in pure rolling motion (after Lee et al. [25]).

Taking into consideration the worst case scenario of rough steel surfaces with $\delta=0.05 \mathrm{~mm}$ and a roller radius of $\mathrm{R}=20 \mathrm{~mm}$, the parasitic roller friction force acting on the beam-column joint of the physical experiment is calculated equal to $\mathrm{f}_{1}=0.125 \mathrm{kN}$ (for axial compressive load per column at $\mathrm{N}=50 \mathrm{kN}$ ) (Fig. 6). The developing parasitic moment on the beam-column joint can be estimated by multiplying $f_{1}$ with the distance from the joint centroid that is equal to $100 \mathrm{~mm}$ (half the beam cross-section depth). The obtained moment value is equal to $0.0125 \mathrm{kNm}$, which is negligible compared to the ultimate bending moment $\mathrm{M}_{\mathrm{u}}=7.3 \mathrm{kNm}$ of the column and cannot affect the inelastic response of the frame. Nevertheless, it is important to check the smooth roller function during the experiment to verify that sliding behavior is avoided.

Another side effect of the roller configuration emanates from the inherent eccentricity of the vertical loads on the columns. A system of four tensioned rebars is used to impose vertical loading on the columns, transferring the force between the steel plates through the roller bearings (Figs. 2 and 4). During the seismic loading, the frame is subjected to horizontal displacement resulting in a roller motion. The upper steel plate, connected to the tensioned rebars, remains essentially fixed in its initial position, introducing an eccentricity of the vertical load to the centroid of the beam-column joint (Fig. 7). Despite the employment of the second steel plate that is adhered to the top of the beam-column joint, the application of the vertical force resembles point loading on the top joint face. An additional second-order moment equal to e $\mathrm{N}$ is therefore imposed on the joint, increasing the column's bending moment. Of course this is an approximate calculation, since the actual roller-joint contact is a small surface area and not a single point, yet it is a justified assumption to obtain some indicative parasitic moment values. The maximum second-order moments, corresponding to the horizontal displacement of the frame at each loading cycle, are calculated in (Table 1). Taking into consideration that the ultimate bending moment $\mathrm{M}_{\mathrm{u}}$ for the column ends is equal to $7.3 \mathrm{kNm}$, the additional moment is expected to have a rather important effect especially after the first few loading cycles.

The aforementioned experimental configuration, using roller bearings to transfer horizontal and vertical loading, is not first appearing during the described research. A similar setup that was successfully used by Stylianidis $[27,28]$, as well as single-story one-bay frames that have been widely used in the literature $[29,30]$, prove that despite few inherent modeling uncertainties this connection type can be quite efficient. In several cases though, the issues that were previously discussed should be taken into consideration during the simulation of the experiment and the evaluation of the frame response.
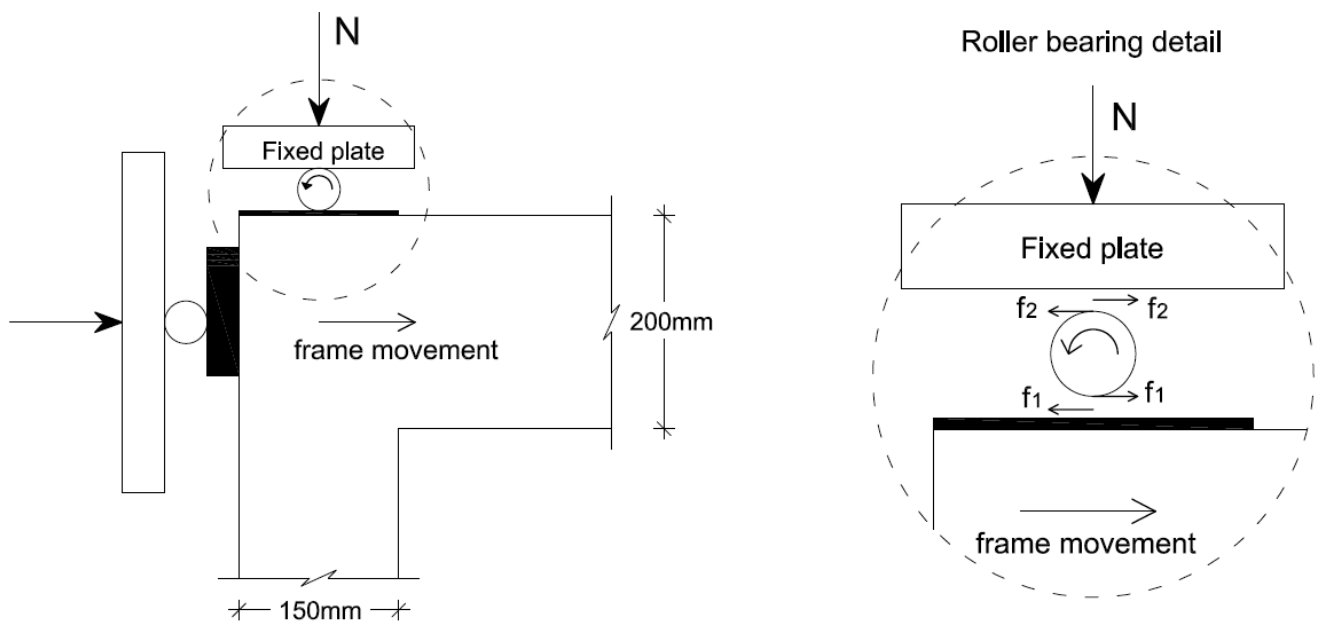

Fig. (6). Parasitic horizontal force $f_{1}$ on the beam-column joint due to roller friction forces. 

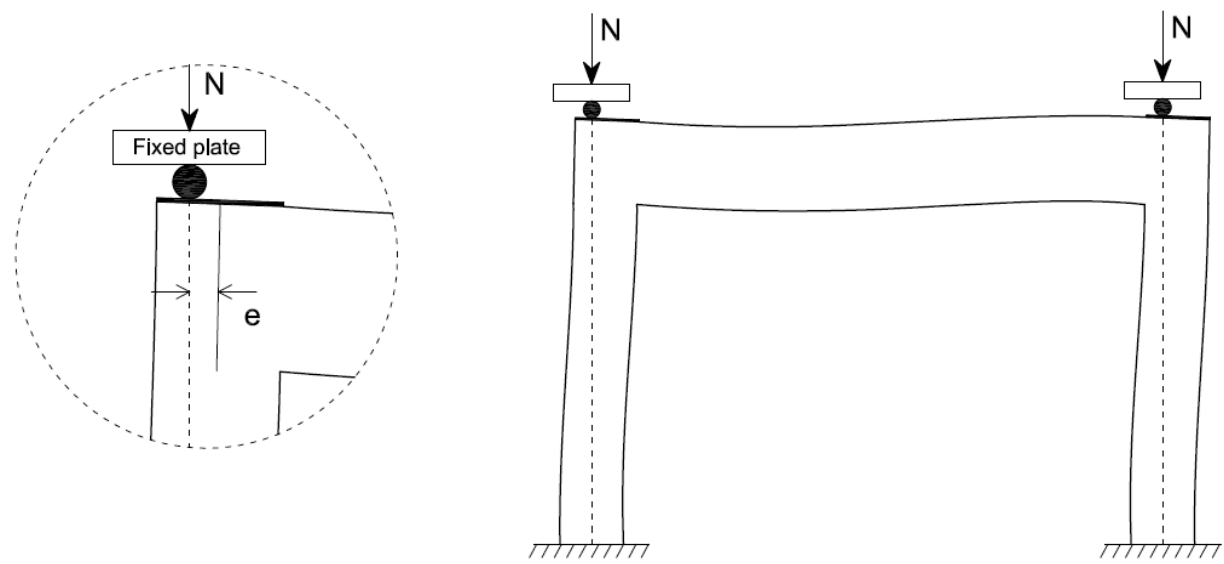

Fig. (7). Eccentric vertical loading of the columns.

Table 1. Maximum Values of Additional Moment on Column's Top End

\begin{tabular}{|c|c|c|c|c|}
\hline Cycle no. & Moment & Cycle no. & Moment & Cycle no. \\
\hline \hline $1-2$ & $0.11 \mathrm{kNm}$ & $7-8$ & $0.93 \mathrm{kNm}$ & $13-14$ \\
\cline { 1 - 4 } $3-4$ & $0.32 \mathrm{kNm}$ & $9-10$ & $1.24 \mathrm{kNm}$ & \\
\cline { 1 - 4 } $5-6$ & $0.63 \mathrm{kNm}$ & $11-12$ & $1.52 \mathrm{kNm}$ & \\
\hline
\end{tabular}

Application of the horizontal displacement on the beamcolumn joint through a roller-plate system does not introduce similar parasitic forces on the frame, since the second-order vertical movement during the cyclic loading is negligible. Nevertheless, the edges of the vertical plate adhered to the external face of the joint where the horizontal load is transferred, create a possible "vulnerable" area where concentrated stresses may cause surficial cracks or even contribute to a premature local concrete failure. Such effect complicates even more the concrete joint behavior, which is not expected to remain elastic under heavy horizontal loading.

Apart from the boundary effects, the model scale is also expected to affect several other response and behavioral parameters. Aggregate interlock plays an important role in the behavior of cracked regions, having a potentially large effect on energy dissipation characteristics [23]. Use of smooth bar reinforcement, dictated by the small bar size requirement due to model scaling, is also expected to influence plastic hinge behavior to an extend [31]. Those factors cannot be easily avoided and should always be taken into consideration during the inspection of the experiment results.

\section{NUMERICAL SIMULATION SCHEME AND SEN- SITIVITY ANALYSIS}

The numerical code Seismostruct [10] is utilized for the numerical simulations of the described experiments. Simulation of reinforced concrete inelastic behavior is achieved using distributed inelasticity elements with force-based formulation, according to the fiber approach. Each fiber is associated with a uniaxial stress-strain relationship, whereas the cross sectional stress-strain state of beam and column elements is obtained through the integration of the nonlinear uniaxial stress-strain response of the individual fibers in which the section has been subdivided. Therefore, there is no requirement for moment-curvature analysis of frame elements and subsequent constitutive model calibration that would have been the case if concentrated plasticity models were employed. On the other hand, the applicability of fibertype elements is not always straightforward in situations involving a near-collapse structural behavior, due to their inability to account for phenomena such as rebar buckling and fracture or nonlinear interaction of flexural and shear [32, 33]. Such issues may affect the obtained response and should be considered accordingly, especially when significant sectional softening response is observed.

Inelastic response of beam and column elements is achieved using the recommended infrmFB formulation of Seismostruct. The FB (force-based) formulation is superior compared to a DB (displacement-based) approach, since it does not depend on the assumed sectional constitutive behavior and requires only one frame element per structural member discretization [13]. Alternate modeling approach employing the inelastic-plastic hinge frame element (infrmFBPH) verifies the accuracy and suitability of the infrmFB formulation to reproduce the significant post-peak behavior range exhibited during the physical experiments. The number of individual fibers used in each section is at least 200, exceeding the minimum recommended value of 100-150 fibers.

The concrete material is simulated using the constitutive law proposed by Mander et al. [14], employing a compressive strength value of $25.00 \mathrm{MPa}$ for cylindrical $100 \times 200 \mathrm{~mm}$ specimens (corresponding to the $28.51 \mathrm{MPa}$ strength of the examined $150 \mathrm{~mm}$ cubic specimens). Since the experimental 
data concerning the concrete compressive strength presented a considerable scatter [11], the complementary analyses that were performed with $\pm 5.00 \mathrm{MPa}$ concrete compressive strength (one standard deviation), revealed negligible effect on the obtained response for the specific frame, both at local and global level.

The reinforcement steel constitutive behavior is based on the stress-strain relationship proposed by Menegotto and Pinto [15], along with certain modifications as described in Seismostruct manual. The yield stress of longitudinal and transverse steel is set to $390.47 \mathrm{MPa}$ and $212.2 \mathrm{MPa}$ respectively, according to preceding material testing, with an elasticity modulus equal to $200 \mathrm{GPa}$. According to Prota et al. [31], the main features of the aforementioned model are sufficiently efficient at modeling the cyclic curves of smooth steel bars at $\mathrm{L} / \mathrm{D}$ ratio ranges below 8 , which is the case for the experiments investigated herein. Finally, the existence of common-type or spiral shear reinforcement in various specimens was not investigated in detail, since the results of the physical experiments did not reveal significant effect on the obtained response as described by Kakaletsis et al. [22].

The effect of specific simulation parameters, concerning either the material and cross-sectional properties or different numerical simulation options and approaches, is investigated thoroughly using sensitivity analysis, as also suggested by the Seismostruct user's manual, to verify the stability and consistency of analysis results. The employed numerical procedure is expected to be used in future experimental efforts, where a priori calibration of numerical simulations is not possible and blind prediction is required. On that account, presentation of only the "optimum" simulation results does not necessarily mean that the selected procedure is suitable to reproduce the frame response under different geometric, material or loading properties. The sensitivity analysis is therefore expected to reveal the range of acceptable results using different modeling scenarios in terms of numerical parameter values and modeling techniques. Special consideration is also given to the reproduction of specific aspects of the scaled physical experiment, as will be presented in detail in the following sections.

\section{NUMERICAL ANALYSIS AND EVALUATION OF RESULTS}

During the numerical analysis procedure, simulation of several parameters required a more thorough approach. Consideration of joint rigidity at the ends of the structural elements is common during the analysis of RC structures and is found to be quite influential on the response of the examined frame. The application of the vertical axial loading on the columns during the physical experiment differs substantially from the compressive column loading of real structures and is examined thoroughly using complementary parasitic moments at the beam-column joints, as described in the previous sections. Geometric non-linearities and P-delta effects that would efficiently take into account the eccentric axial loading in realistic structural models, have an entirely different nature in the experimental frame and should be treated carefully during the analysis. The same attention is given to the simulation of the concrete beam behavior, where the developing compressive axial force during testing is not negligible, affecting the strength of the element. Apart from the parameters related to aspects of the physical experiment, numerical analysis also comprises of different plausible simulation techniques and alternate options that need an elaborate approach.

In the following section, several of the above issues that were resolved using alternate simulation schemes or sensitivity analysis are presented and discussed, along with the evaluation of the final results. A large number of model configurations were examined, employing different combinations of the aforementioned parameters to investigate their individual effect on the frame response. Indicative examined numerical models and their properties are presented in (Table 2). Although the analysis procedure was stable in most cases, few combinations of the examined analysis parameters resulted in local abnormalities of the obtained response. Therefore all analyses results were carefully inspected before considered valid for evaluation.

\subsection{Beam and Column Rigid End Offsets}

The geometrical configuration of the frame model was obtained using the axial dimensions of the individual concrete members. In order to define the exact length of each element subjected to bending, the rigid offset option of element connectivity in Seismostruct is employed. This option is used to prevent bending of both column and beam elements inside the joint area. Although it is acknowledged that the beam-column joint area reduces the length of the adjacent structural elements, the exact behavior of concrete joints under cyclic loading is under research and there is still no agreement on a uniformly applied approach. Several models have been proposed to simulate joint flexibility and degradation under large drift cycles related to seismic loading [34, 35]. Commercial and academic finite element software consider the joint flexibility by employing semi-rigid ends at RC elements, introducing an empirical stiffness reduction coefficient [36]. An alternative proposal by Elwood et al. [37], introduces the concept of reduced rigidity length of the beam and column elements inside the joint, depending on the column to beam flexural strength ratio. The detailed simulation of the flexural and shear response of the beam-column joint is beyond the scope of the present paper. Nevertheless, it was considered significant to investigate the rigid end effect on the analysis results, even under the extreme assumption of fully rigid ends of the beam and column length within the entire joint area.

It was observed that the use of rigid offsets resulted in a considerable modification of the plastic hinges formation pattern. More specifically, the plastic deformation at the beam ends is reduced, whereas the sections at the top of the columns exhibit inelastic deformation that was not present at the model without any rigid end offsets (Fig. 8). The results presented in this figure are not final, since more physical parameters need to be modeled accordingly, yet the joint rigidity effect is clearly highlighted. Indeed, introducing rigid end offsets actually reduces the column length, resulting in a subsequent increase of the developing bending moment for the same amount of imposed horizontal displacement on the frame. The obtained plastic hinge formation pattern is in agreement with the observations that were made during the physical experiments, where inelastic behavior was also identified at the top of the columns [11,22]. 
Table 2. Properties of Indicative Examined Numerical Models

\begin{tabular}{|c|c|c|c|c|c|}
\hline $\begin{array}{l}\text { Numerical } \\
\text { Model }\end{array}$ & Rigid ends & $\begin{array}{c}\text { Deactivation of Geometrical } \\
\text { non-linearities }\end{array}$ & Eccentricity moment & $\begin{array}{c}\text { Beam compression only } \\
\text { (links) }\end{array}$ & Integration sections \\
\hline Frame B-3 & - & - & - & - & 3 \\
\hline Frame BR-3 & $\sqrt{ }$ & - & - & - & 3 \\
\hline Frame BRL-3 & $\sqrt{ }$ & - & - & $\sqrt{ }$ & 3 \\
\hline Frame BRMGL-3 & $\sqrt{ }$ & $\sqrt{ }$ & $\sqrt{ }$ & $\sqrt{ }$ & 3 \\
\hline Frame BRMGL-5 & $\sqrt{ }$ & $\sqrt{ }$ & $\sqrt{ }$ & $\sqrt{ }$ & 5 \\
\hline
\end{tabular}

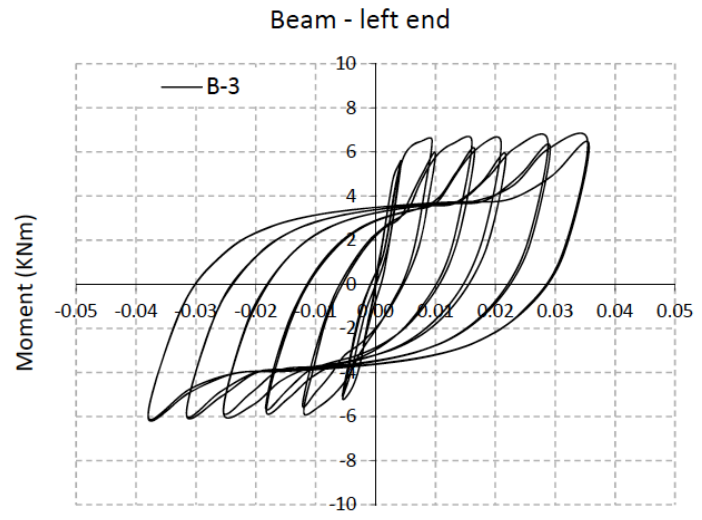

Rotation $\theta$ (rad)

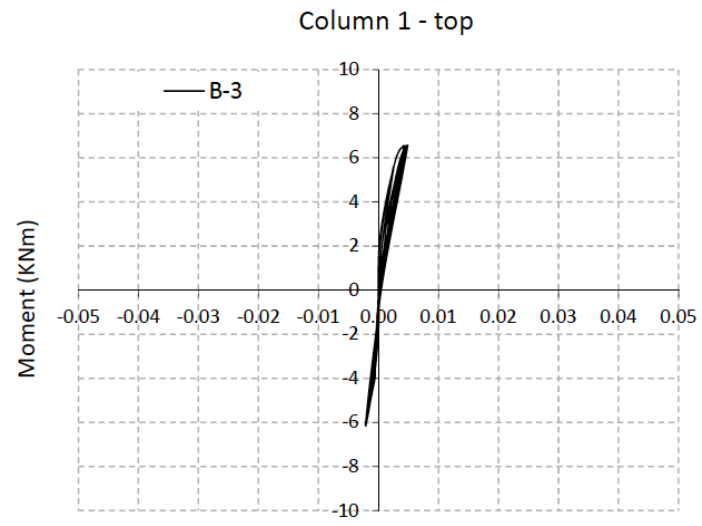

Rotation $\theta$ (rad)

(a) model without element rigid ends

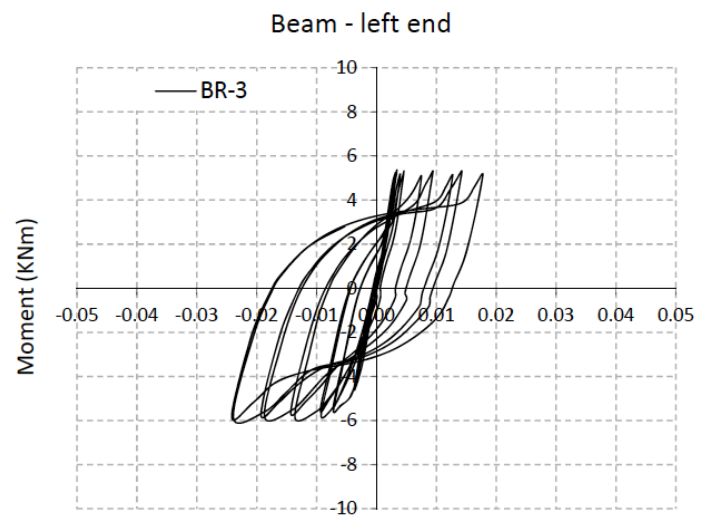

Rotation $\theta$ (rad)

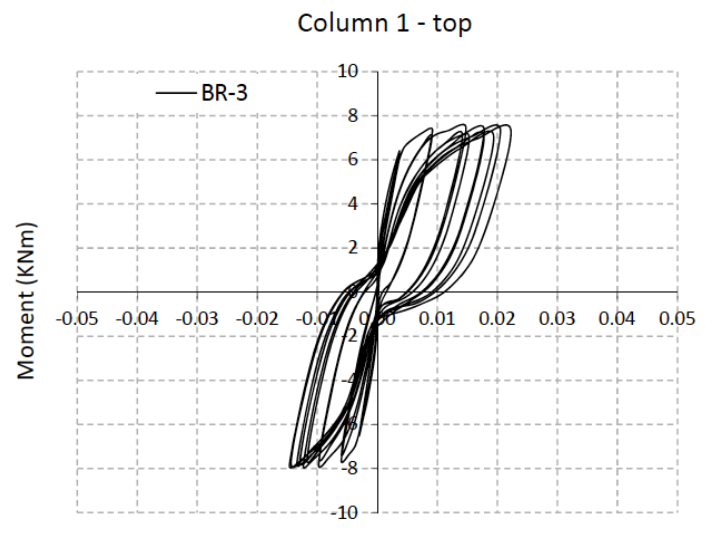

Rotation $\theta$ (rad)

(b) model with element rigid ends

Fig. (8). Moment-rotation loops indicating the effect of element rigid ends on plastic hinge formation at the top of the column and respective end of the beam.

\subsection{Geometric Non-Linearities}

Another potentially important factor affecting the response of the frame is the second-order moment imposed by the eccentric vertical loading of the columns during the experimental testing that was previously discussed (Fig. 7). In order to take this effect into consideration, the moment values calculated at (Table 1) were applied as external loading at the top beam-column joints of the frame. The moment values were increasing during the analysis, corresponding to the displacement level of each loading cycle. As mentioned 
earlier, the calculated moment values are somehow exaggerated, since application of axial loading is not strictly on one specific point, yet they provide some indicative numbers to check the effect on the model. A sensitivity analysis implicating different modeling configurations, i.e. with or without rigid end offsets, different number of integration sections at elements etc, revealed a minor effect on the global frame response, yet resulted in a rather significant modification of elements behavior at local level.

More specifically, the thickness of the forcedisplacement loops of the frame (global level response) slightly decreased when the additional moment loading was introduced, improving marginally the comparison with the obtained experimental results. On the other hand, all examined modeling approaches revealed a clear reduction of plastic hinge extent at the beam, accompanied by an increase of the corresponding plastic deformation at the top end of the column (Fig. 9). This observation is consistent with the physical experiments where columns presented considerable inelastic response at the top beam-column joints.

The aforementioned effect is more accurately taken into account when the default option of Seismostruct to include geometric non-linearities is deactivated. Indeed, P-delta effects in a common structure correspond mainly to the eccen- tric axial loading of columns with respect to the support at the base of the element. In this experimental setup though, Pdelta effects are completely different, since the eccentricity is introduced between the vertical load application point and the top joint of the frame (Fig. 7). On the other hand, the axial load is concentric towards the base cross-section of the column. When the automatic calculation of geometric nonlinearities is deactivated in the numerical code, the effect on the cross sectional behavior is negligible, yet the overall frame response is affected presenting an increase of the postelastic strength as described during the evaluation of the final results in a following section of the paper.

\subsection{Axial Force on Beam}

The horizontal loading imposed during the experiment results in axial loading of the beam element. These forces are negligible in real structures, where the horizontal earthquake loading is distributed on the floor and the large in-plane stiffness of the concrete slab prevents the development of large axial forces on beams. The case of the investigated physical experiment though is different, since the axial force is acting directly on the beam, due to the lack of concrete slab. Moreover, the loading configuration of the physical experiment always results in compression of the beam, since
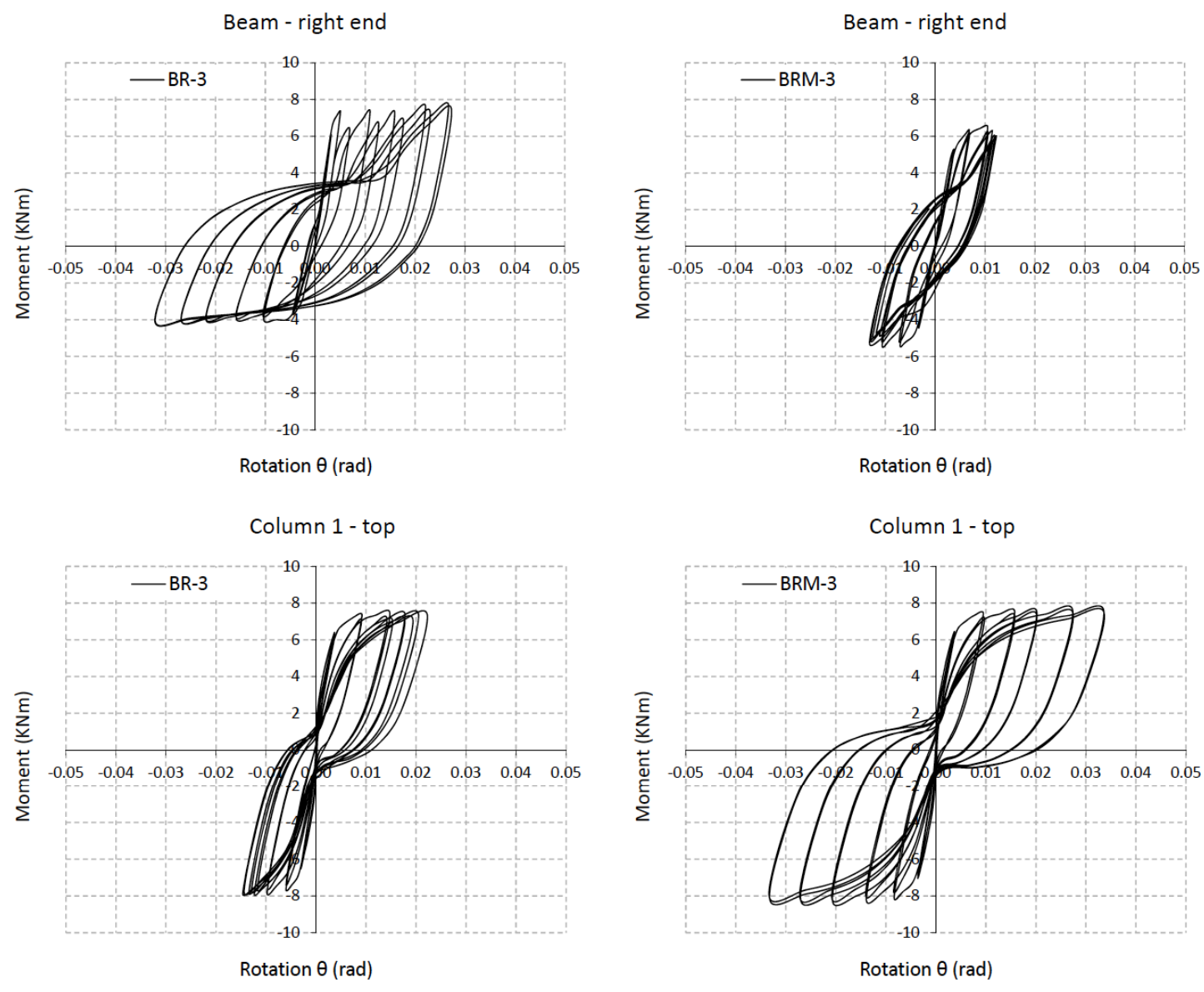

(a) initial model

(b) model with eccentricity moment

Fig. (9). Moment-rotation loops indicating reduction of plastic deformation at the beam and increase at the top column cross-section when eccentricity moment is applied. 
when the direction of the loading changes, the displacement is imposed on the opposite joint of the frame. Therefore the beam is never in tension, something that is not always considered during simulation in several modeling efforts in the literature.

In order to establish a compression-only loading of the beam during the numerical simulations in Seismostruct, a gap-hook type link element was employed at the top joints of the frame. The displacement time-history was imposed on both end nodes of the link elements, yet appropriate element properties configuration permitted only the application of compressive loading on the beam, activating successively the left or right link element according to the direction of the movement. The effect on the frame response is obvious both in local and global scale. The post-elastic strength of the frame increases in the direction associated with the negative displacement (model BRL-3 in Fig. 10), improving the comparison with the experimental Specimens B and BS. It is reminded that this movement direction was erroneously inducing tension at the beam in the previous simulation model BR-3. On the other hand, the compressive force on the beam results in an increased bending moment capacity, preventing the formation of plastic hinge at the beam ends and increasing the plastic deformation of the columns.

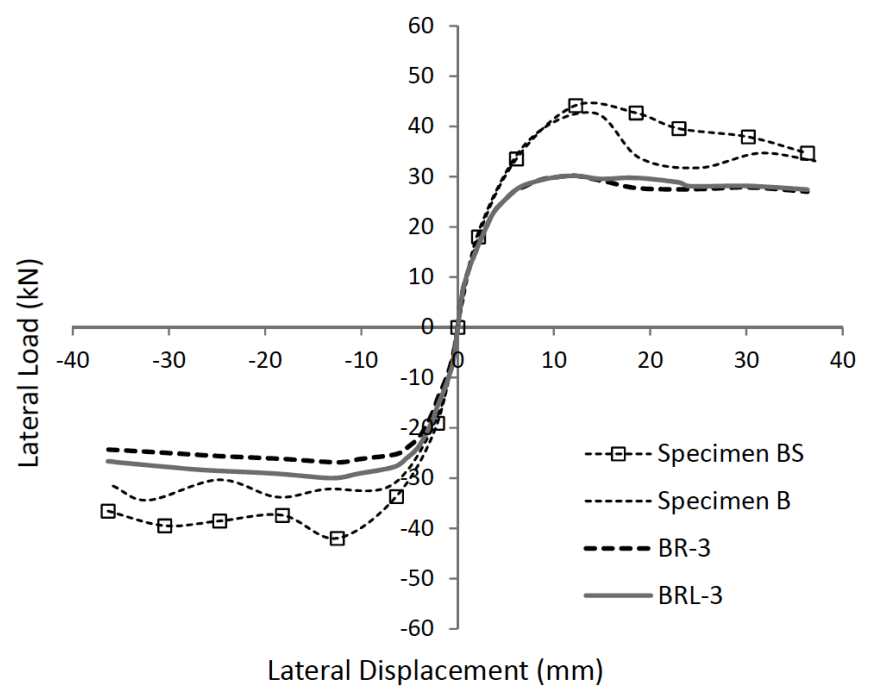

Fig. (10). Effect of beam axial loading on the response of the frame; model BRL-3 prevents beam tension during the analysis, resulting in increased frame strength.

\subsection{Numerical Issues}

In order to account for the numerical issues related to the FB element formulation that were presented by Calabrese et al. [13], a sensitivity study was also conducted concerning the number of integration sections and individual fibers per section employed during the analysis. Comparative evaluation of the results revealed that increase of integration sections has a thickening effect on the moment-rotation loops of the column ends and, in consequence, on the forcedisplacement loops of the frame (Fig. 11a and 11b). On the other hand, the 200 fibers employed in the section's discretization are sufficient to provide consistent results, as complementary analyses with larger number of fibers presented negligible difference. Yet, in few cases it was necessary to increase the fiber number, in order to overcome local shape abnormalities of individual moment-rotation loops or to achieve convergence of the analysis procedure.

Since the results of the physical experiments were characterized by a considerable post-peak behavior range, yet without significant softening sectional response, the inelastic plastic hinge frame element (infrmFBPH) was also utilized as more suitable in such response cases to overcome possible localization issues [13]. This element features a similar distributed inelasticity formulation with the previously employed infrmFB element, only this time inelasticity is concentrated within a fixed length of the element. The simulation results were in good agreement with the infrmFB elements, yielding relatively narrow force-displacement loops that compared well with the loops obtained from the experimental procedure (Fig. 11c). Slight adjustment of the plastichinge length of the infrmFBPH element may result in minor alterations of the obtained loops shape and thickness.

\subsection{Final Results and Discussion}

Comparison between numerical and experimental results at global level, in terms of force-displacement diagrams for the frame depicted in Fig. (12a), reveals that numerical simulation yields $10-20 \%$ lower horizontal strength values at the post-elastic response range (experimental specimens $\mathrm{B}$ and BS). This figure includes results from several analysis approaches, with and without the consideration of parameters such as element rigid ends, second-order moment from eccentric axial loading, tension-only forces at the beam etc. A detail of the force-displacement diagrams for selected numerical models is presented in Fig. (12b), focusing on the negative displacement direction where the effect of the beam compression on the response is most prominent. It is clear that consideration of the loading eccentricity at the columns (BRM-3), as well as of the compression-only loading of the beam (BRL-3), results in increased strength of the frame. When all examined parameters are combined in the same simulation model (BRMGL-P), the obtained forcedisplacement curves are at the high end of the presented numerical results, approaching the experimental models. The results are closer to the experimental Specimen B that employs common rectangular stirrups for the shear reinforcement of concrete cross-sections, similar to the adopted numerical models.

Individual force-displacement loops for the analysis model BRMGL, that considers all the physical factors and numerical parameters described in the previous sections, are presented for indicative loading cycles in Fig. (11). The comparison of the obtained force-displacement loops reveals the efficiency of the numerical simulation to reproduce the experimental behavior, especially when a small number of integration sections is employed. Use of the inelastic plastic hinge frame element formulation provides similar results, with loop thickness matching the experimental findings as long as the plastic hinge length is set to a value close to 13$15 \%$ of the element length.

The global inelastic response of the frame is therefore slightly underestimated, yet simulations predict satisfactorily the overall behavior whereas numerical results are consistent 


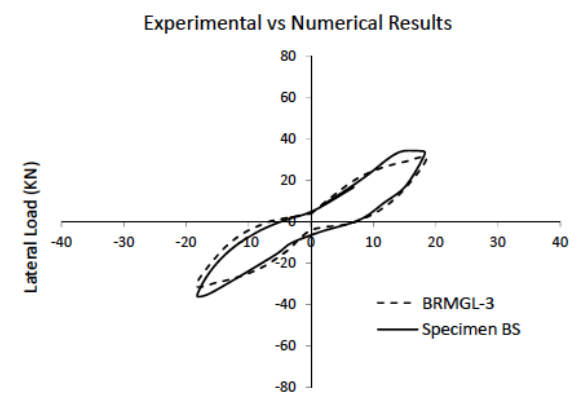

Lateral displacement (mm)

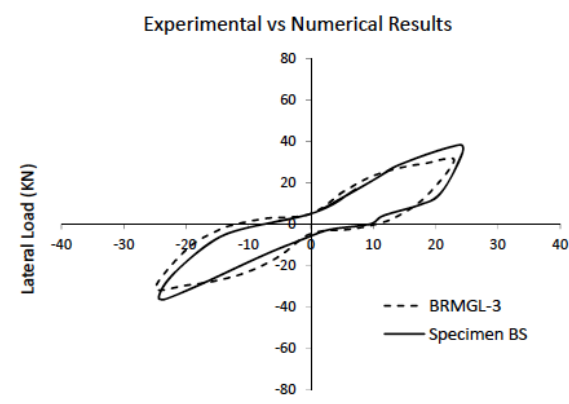

Lateral displacement (mm)

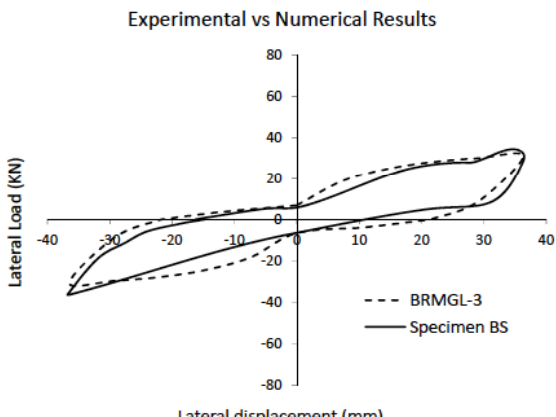

(a) infrmFB element

(3 integration sections)

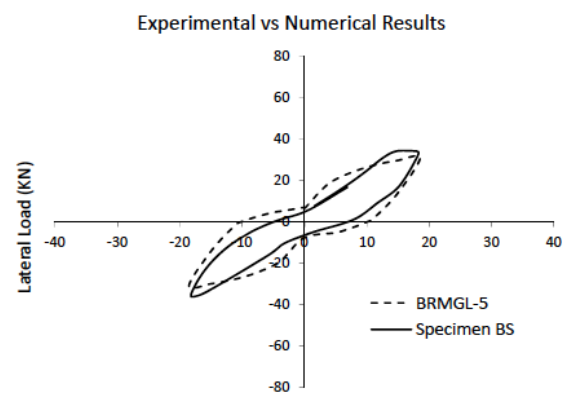

Lateral displacement (mm)

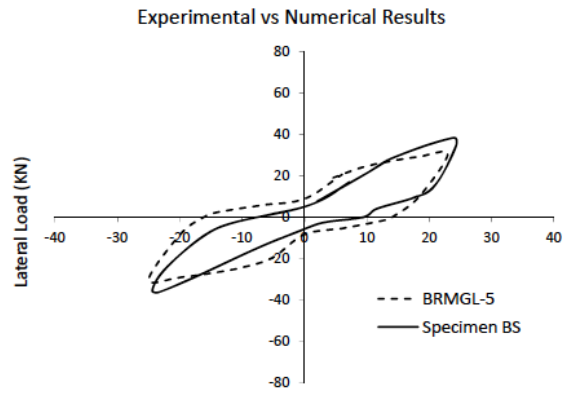

Lateral displacement (mm)

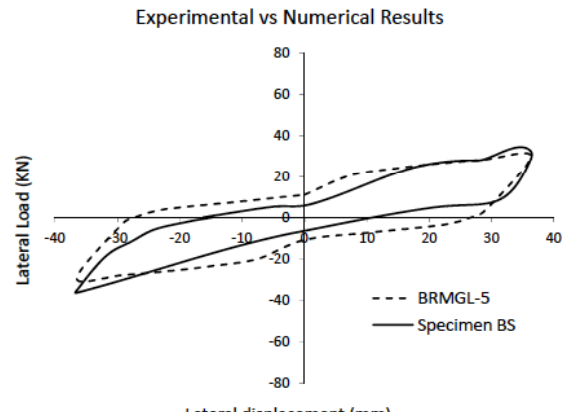

Lateral displacement $(\mathrm{mm})$

(b) infrmFB element

(5 integration sections)

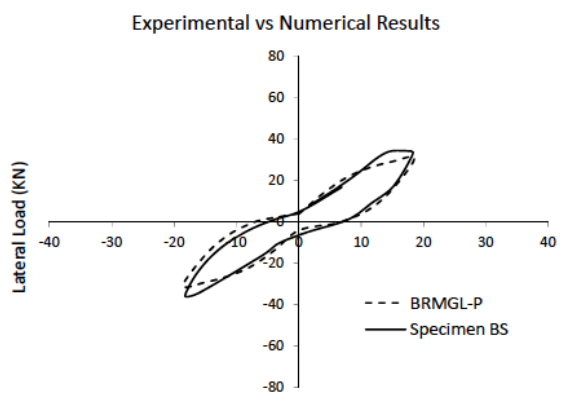

Lateral displacement (mm)

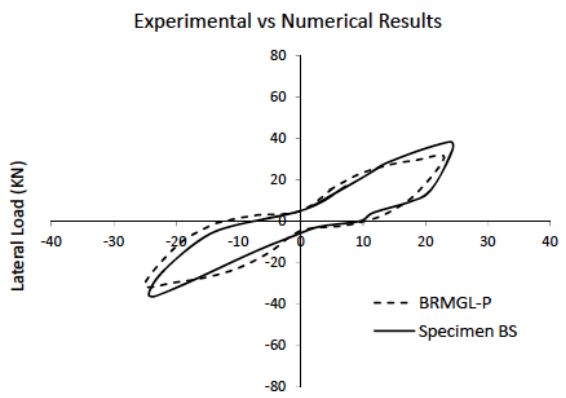

Lateral displacement (mm)

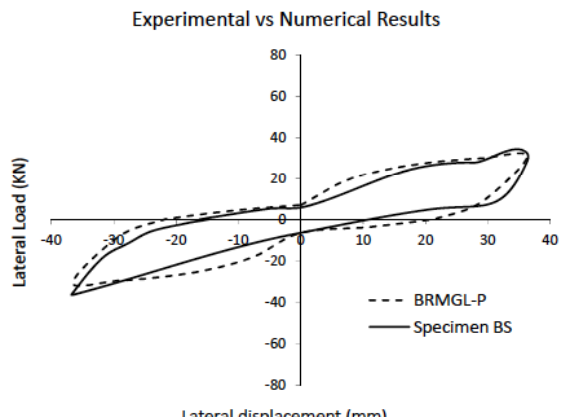

Lateral displacement $(\mathrm{mm})$

(c) infrmFBPH element

Fig. (11). Force-displacement loops of the frame (indicative loading cycles) for different numerical modeling approaches - comparison with experimental Specimen BS.

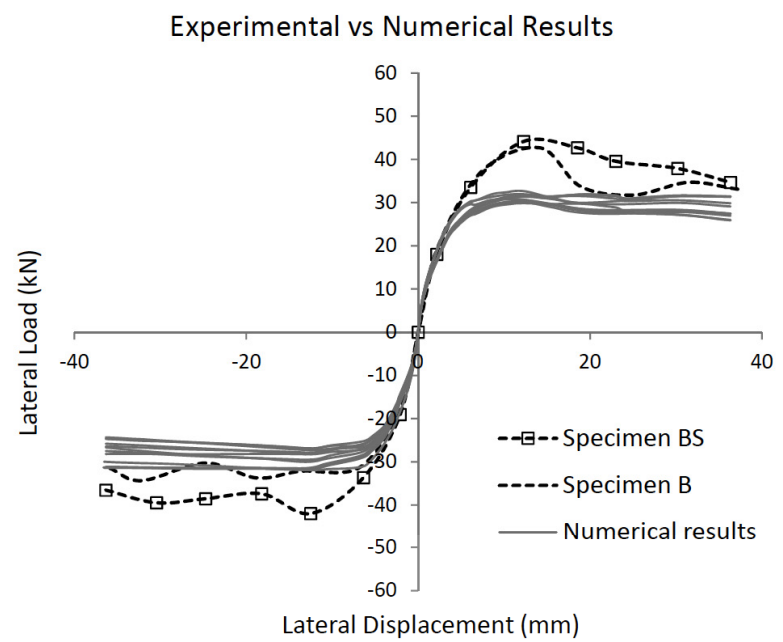

(a)

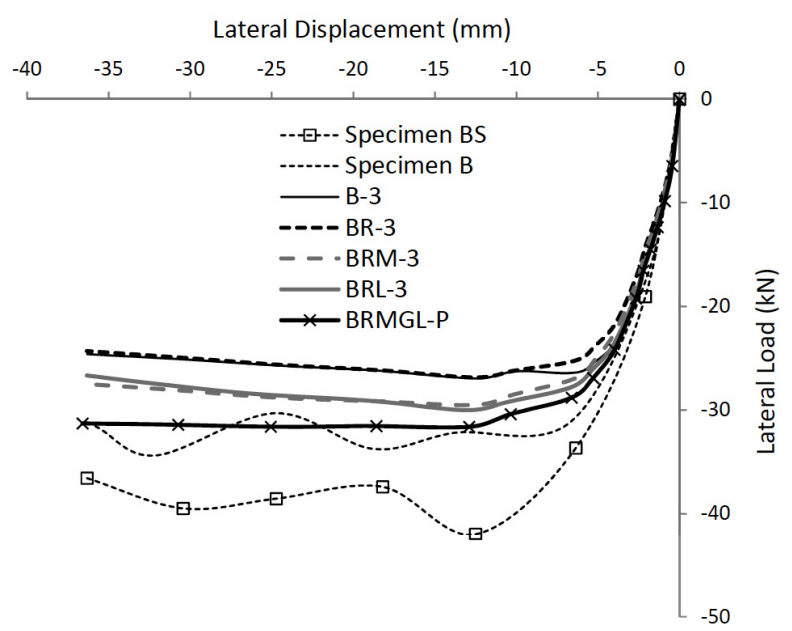

(b)

Fig. (12). Force-displacement curves; comparison between experimental and numerical results (a) several numerical approaches and (b) detail of selected analyses results. 
between different analysis schemes, regardless of the specific selected parameter values.

Moment-rotation loops at sectional level are more sensitive to different analysis approaches and parameter selections. It is already displayed that the inelastic response pattern changes when rigid end offsets are employed at elements during the analysis, resulting in plastic hinge formation at column ends and reducing the beam inelastic deformation at the beam-column joints (Fig. 8). When the simulation procedure prevents beam tension, corresponding to the loading setup of the physical experiment where the imposed horizontal deformation results always in beam compression, the beam moment capacity increases and the plastic response at the ends is limited. Consideration of the second-order moment at the beam-column joint due to axial load eccentricity of columns has a similar, yet less prominent, effect. The obtained results explain adequately the formation of plastic hinges at the top of the columns, despite the adopted mean column-to-beam bending moment strength ratio of 1.40. Parameters related to numerical analysis options, such as the number of fibers per section or the number of integration sections at the element, affect the analysis results only qualitatively, i.e. altering slightly the thickness or shape of moment-rotation loops.

Indicative moment-rotation loops of several frame crosssections are depicted in Fig. (13) for numerical model BRMGL. It is obvious that the plastic hinge of the joint is

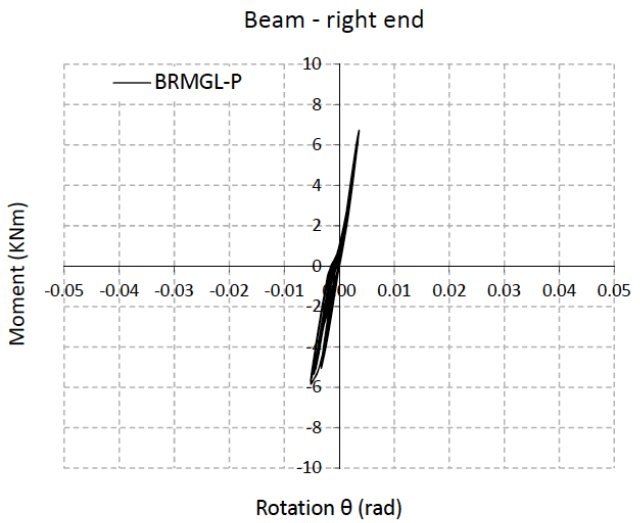

(a)

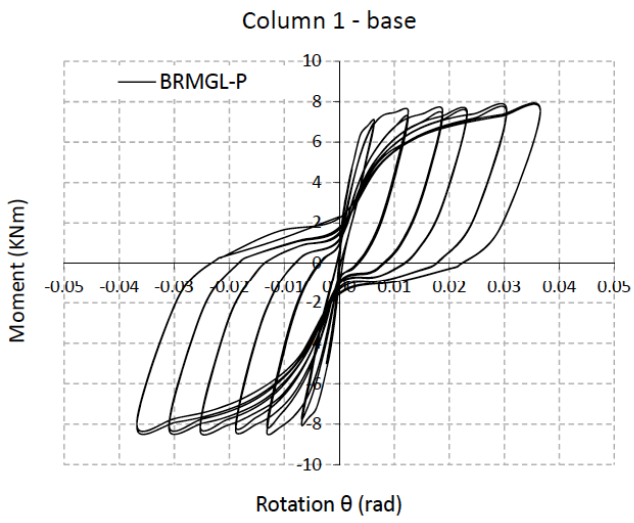

(c) developed at the top of the column, whereas the beam remains at the onset of plastic deformation, overcoming just the yield initiation level. On the other hand, the base of both columns presents significant levels of inelastic deformation with plastic hinge rotation values of $0.037 \mathrm{rad}$, very close to the $0.034 \mathrm{rad}$ measurement of the physical experiment [38], as presented in (Table 3). The plastic rotation value of 0.005 $\mathrm{rad}$ at the beam is equal to the experimental value, whereas numerical calculations overestimate the plastic deformation at the top of the columns, yielding plastic rotation values of $0.033 \mathrm{rad}$ compared to $0.027 \mathrm{rad}$ of the physical testing findings. It should be taken into consideration that the BRMGL model incorporates the full extent of all the parameters affecting the response of the frame. The member ends are considered with full rigidity for the entire joint area, the complementary eccentricity moment imposed on the beamcolumn joint is calculated using strict assumptions regarding the exact vertical loading point etc. Since several aspects of those parameters are still under research, the exact numerical simulation of their effects is not straightforward and a sensitivity analysis should be carried out to identify any deviant response patterns.

The similar frame response at global level, regardless of the exact plastic hinge formation order, is attributed to the design and detailing of all beam and column cross-sections that ensure increased ductility under severe plastic deformations. Therefore, the same global behavior was met even in

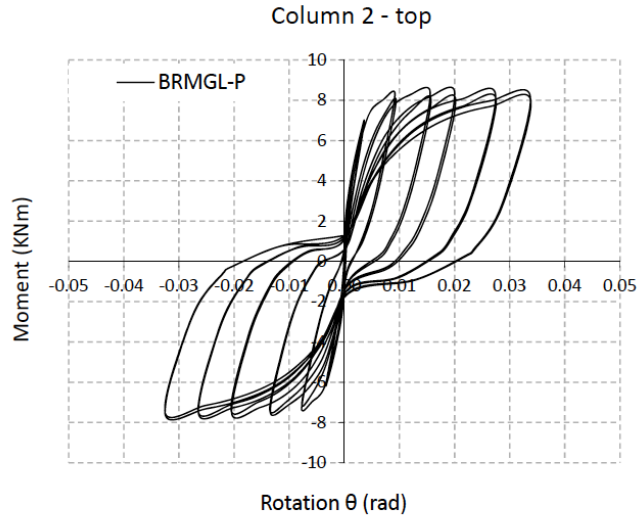

(b)

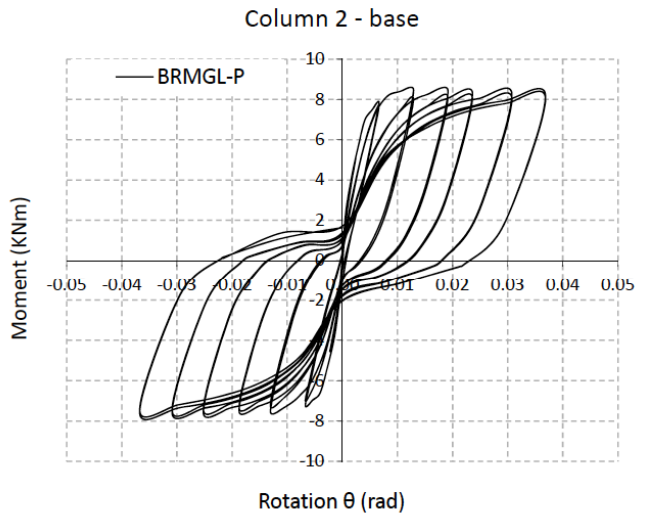

(d)

Fig. (13). Moment-rotation curves for beam and column cross-sections. 
Table 3. Ultimate Plastic Hinge Rotations at Critical Sections

\begin{tabular}{|c|c|c|c|c|c|c|}
\hline & \multicolumn{6}{|c|}{ Plastic hinge rotation (rad) } \\
\hline & \multicolumn{2}{|c|}{ Left Column } & \multicolumn{2}{|c|}{ Right Column* } & \multicolumn{2}{|c|}{ Beam } \\
\hline & Base & Top & Base & Top & Left & Right \\
\hline Physical experiment & 0.034 & 0.027 & - & - & 0.005 & 0.005 \\
\hline $\begin{array}{l}\text { Simulation } \\
\text { BRMGL-P }\end{array}$ & 0.037 & 0.033 & 0.038 & 0.033 & 0.003 & 0.005 \\
\hline
\end{tabular}

*Experimental results were available only for the left column

case of frames that do not follow adequately the capacity design requirements at beam-column joints. Yet, this observation is restricted to configurations similar to the examined single-story frame and should not be generalized to more complex structures. If multi-story frames were investigated, the formation of plastic hinges at columns instead of beam ends would have been expected to present a much more unfavorable effect on the structural integrity. Indeed, severe plastic deformation of columns, especially when concentrated at the base floor of the structure, would reduce significantly the vertical load bearing capacity of the columns, leading even to structural collapse. On the other hand, when capacity design concepts are applied, the plastic hinge formation at beams ensures adequate absorption of earthquake energy and a failure mechanism that efficiently prevents partial or total structural collapse.

\section{CONCLUSIONS}

During the simulation of physical experiments, several parameters concerning physical aspects of the testing procedure or numerical options related to the employed analysis code should be determined before deciding on an efficient simulation approach. The scope of the present paper was to examine the effect of those parameters in the case of bare RC frames under horizontal cyclic loading and to conclude on a simulation approach that would yield satisfactory results, even under slightly different choices during modeling. To this end, an extensive numerical procedure was implemented, investigating the effect of parameters such as the beam-column joint rigidity, geometrical nonlinearities, eccentric axial loading of columns and axial force development at the beam. The numerical code Seismostruct was used during the simulation process whereas the physical experiments that were investigated are described by Kakaletsis [11].

The consideration of rigid lengths at the ends of the elements played an important role on the response, especially at cross-sectional level. The reduction of columns length resulted in the formation of plastic hinge at the top end, reducing at the same time the inelastic deformation of the beam. Similar effect was observed when the numerical modeling approach prevented tension from the beam, conforming to the physical experiment setup that imposed only compression during the successive loading cycles. Moreover, application of complementary moment-type loading at the beamcolumn joint, emanating from the eccentric axial loading of the columns due to the specific experimental configuration, also drives plastic hinge formation from beam ends to the adjacent column cross-sections. The combined effect of the aforementioned parameters is therefore reducing inelastic response at the beam and increases plastic deformation at the top of the columns, a result that is in accordance with the physical experiment observations.

At global level on the contrary, the obtained frame forcedeformation curve is only slightly modified between different numerical model approaches. This observation is restricted to single story structural configurations similar to the examined frame, and is attributed to the ductile design of all concrete members, which provides satisfactory post-elastic response for the frame, regardless the exact pattern of plastic hinge formation. Nevertheless, consideration of all the implicated parameters improves the comparison between analysis and experimental findings.

Conclusively, the employed numerical approach predicts quite efficiently the behavior at global level of ductile bare concrete frames under cyclic loading, without the requirement of thorough modeling configuration or calibration procedures. To achieve a fair simulation of the response at cross-sectional level though, a more detailed modeling scheme should be followed, considering the influential parameters of the experimental response that were investigated in the present paper.

\section{CONFLICT OF INTEREST}

The author(s) confirm that this article content has no conflicts of interest.

\section{ACKNOWLEDGEMENT}

Declared none.

\section{REFERENCES}

[1] M.N. Fardis, and T.B. Panagiotakos, "Seismic design and response of bare and masonry-infilled reinforced concrete buildings. Part I: bare structures", Journal of Earthquake Engineering, vol. 1, pp. 219-256, 1997.

[2] E. Smyrou, C. Blandon, S. Antoniou, R. Pinho, and F.J. Crisafulli, "Implementation and verification of a masonry panel model for nonlinear dynamic analysis of infilled RC frames", Bulletin of Earthquake Engineering, vol. 9, pp. 1519-1534, 2011

[3] A. Kappos, K.C. Stylianidis, and C.N. Michailidis, "Analytical Models for Brick Masonry Infilled R/C Frames under Lateral Loading", Journal of Earthquake Engineering, vol. 2, pp. 59-87, 1998.

[4] G.C. Manos, V.J. Soulis, and J. Thawambteh, "A nonlinear numerical model and its utilization in simulating the in-plane behav- 
iour of multi-story R/C frames with masonry infills", The Open Construction and Building Technology Journal, vol. 6, pp. 254277, 2012

[5] P.G. Asteris, and D.M. Cotsovos, "Numerical investigation of the effect of infill walls on the structural response of RC frames", The Open Construction and Building Technology Journal, vol. 6, pp. 164-181, 2012.

[6] F. Ellul, and D. D' Ayala, "Realistic FE models to enable push-over non linear analysis of masonry infilled frames", The Open Construction and Building Technology Journal, vol. 6, pp. 213-235, 2012.

[7] E. Kirtas, E. Rovithis, and K. Pitilakis, "Subsoil interventions effect on structural seismic response. Part I: validation of numerical simulations", Journal of Earthquake Engineering, vol. 13, pp. 155-169, 2009.

[8] E. Rovithis, E. Kirtas, and K. Pitilakis, "Experimental p-y loops for estimating seismic soil-pile interaction", Bulletin of Earthquake Engineering, vol. 7, pp. 719-736, 2009

[9] D. Pitilakis, M. Dietz, D. Muir Wood, D. Clouteau, and A. Modaressi, "Numerical simulation of dynamic soil-structure interaction in shaking table testing", Soil Dynamics and Earthquake Engineering, vol. 28, pp. 453-467, 2008.

[10] Seismosoft Ltd., "Seismostruct version 6: User Manual", www.seismosoft.com, Pavia, Italy, 2012.

[11] D.J. Kakaletsis, "Investigation of the Behavior of Orthogonal Masonry Infilled Reinforced Concrete Frames With Openings Under Horizontal Large Amplitude Cyclic Displacements (in Greek)", $\mathrm{PhD}$ Thesis, Civil Engineering Department, Democritus University of Thrace, Greece, 2008.

[12] F.C. Filippou, and G.L. Fenves, "Chapter 6: Methods of Analysis for Earthquake-Resistant Structures", in Earthquake Engineering From Engineering Seismology to Performance-Based Engineering, Y. Bozorgnia and V. V. Bertero, Eds., ed Cambridge, United Kingdom: Cambridge University Press, 2004, pp. 316-393.

[13] A. Calabrese, J.P. Almeida, and R. Pinho, "Numerical Issues in Distributed Inelasticity Modeling of RC Frame Elements for Seismic Analysis", Journal of Earthquake Engineering, vol. 14, pp. 3868, 2010.

[14] J.B. Mander, M.J.N. Priestley, and R. Park, "Theoretical stressstrain model for confined concrete", Journal of Structural Engineering, $A S C E$, vol. 114, pp. 1804-1826, 1988.

[15] M. Menegotto, and P. Pinto, "Method of Analysis for Cyclically Loaded RC Plane Frames Including Changes in Geometry and Non-elastic Behavior of Elements under Combined Normal Force and Bending", in Symposium on the resistance and ultimate deformability of structures acted on by well defined repeated loads, IABSE Reports (4th edn), Lisbon, Portugal, 1973.

[16] Ministry of Public Works, "Greek Reinforced Concrete Code EKOS 2000", Earthquake Planning and Protection Organization EPPO (in Greek), Athens, Greece, 2000.

[17] CEN, European Committee for Standardisation, "EN 1992-1-1: Eurocode 2: Design of Concrete Structures, Part 1-1: General Rules and Rules for Buildings", Brussels, 2004.

[18] CEN, European Committee for Standardization (2004), "EN 19981: Eurocode 8: Design of Structures for Earthquake Resistance, Part 1: General rules, seismic actions and rules for buildings", Brussels, 2004.

[19] D.J. Kakaletsis, and C.G. Karayannis, "Experimental investigation of infilled R/C frames with openings", ACI Structural Journal, vol. 106, pp. 132-141, 2009.

[20] P.G. Asteris, D.J. Kakaletsis, C.Z. Chrysostomou, and E.E. Smyrou, "Failure modes of In-filled frames", Electronic Journal of Structural Engineering, vol. 11, pp. 11-20, 2011

[21] A.B. Mehrabi, P.B. Shing, M.P. Schuller, and J.L. Noland, "Performance of Masonry-Infilled R/C Frames under in-Plane Lateral Loads", Report no. CD/SR-94/6, Department of Civil, Environmental \& Architectural Engineering, University of Colorado at Boulder, 1994.
[22] D.J. Kakaletsis, C.G. Karayannis, and G.K. Panagopoulos, "Effectiveness of rectangular spiral shear reinforcement on infilled $\mathrm{R} / \mathrm{C}$ frames under cyclic loading", Journal of Earthquake Engineering, vol. 15, pp. 1178-1193, 2011.

[23] R.E. Klinger, and V.V. Bertero, "Infilled Frames in EarthquakeResistant Construction", Earthquake Engineering Research Center, University of California, Berkeley EERC-76-32, 1976.

[24] S.T. Brokken, and V.V. Bertero, "Studies on Effects of Infills in Seismic Resistant R/C Construction", Report no. UCB/EERC81/12, Earthquake Engineering Research Center, University of California, Berkeley, 1981.

[25] G.C. Lee, Y.C. Ou, Z. Liang, T. Niu, and J. Song, "Principles and Performance of Roller Seismic Isolation Bearings for Highway Bridges", Report no. MCEER-07-0019, Multidisciplinary Center for Earthquake Engineering Research, University at Buffalo, The State University of New York, 2007.

[26] E.A. Avallone, and T. Baumeister, Marks' standard Handbook for Mechanical Engineers, 10th ed. London, U.K.: McGraw-Hill, 1996.

[27] K.C. Stylianidis, "Experimental Investigation of the Behaviour of Single-Story Infilled R/C Frames under Cyclic Quasi-Static Horizontal Loading - Parametric Analysis", PhD Thesis (in Greek), Civil Engineering Department, Aristotle University of Thessaloniki, 1985.

[28] K.C. Stylianidis, "Experimental Investigation of Masonry Infilled $R / C$ Frames", The Open Construction and Building Technology Journal, vol. 6, pp. 194-212, 2012.

[29] R. Zarnic, and M. Tomazevic, "An Experimentally Obtained Method for Evaluation of the Behaviour of Masonry Infilled R/C Frames", in 9th World Conference on Earthquake Engineering, Tokyo-Kyoto, Japan, 1988.

[30] G.M. Calvi, and D.A. Bolognini, "Seismic response of reinforced concrete frames infilled with weakly reinforced masonry panels", Journal of Earthquake Engineering, vol. 5, no. 2, pp. 153-185, 2001

[31] A. Prota, F. Cicco, and E. Cosenza, "Cyclic behavior of smooth steel reinforcing bars: experimental analysis and modeling issues", Journal of Earthquake Engineering, vol. 13, no. 4, pp. 500-519, 2009

[32] C.B. Haselton, A.B. Liel, G.G. Deierlein, B.S. Dean, and J.H Chou, "Seismic collapse safety of reinforced concrete buildings. I: assessment of ductile moment frames", Journal of Structural Engineering, vol. 137, no. 4, pp. 481-491, 2011.

[33] G.G. Deierlein, A.M. Reinhorn, and M.R. Willford, "Nonlinear Structural Analysis for Seismic Design", NEHRP Seismic Design Technical Brief No. 4, produced by the NEHRP Consultants Joint Venture, a partnership of the Applied Technology Council and the Consortium of Universities for Research in Earthquake Engineering, for the National Institute of Standards and Technology, Gaithersburg, MD, NIST GCR 10-917-5, 2010.

[34] A. Birely, L. Lowes, and D. Lehman, "A model for the practical nonlinear analysis of reinforced-concrete frames including joint fexibility", Engineering Structures, vol. 34, pp. 455-465, 2012.

[35] P. Mergos, and A. Kappos, "A Gradual Spread Inelasticity Model for R/C Beam-Columns, Accounting for Flexure, Shear and Anchorage Slip", Engineering Structures, vol. 44, pp. 94-106, 2012.

[36] CSI - Computers and Structures Inc., "CSI Analysis Reference Manual for SAP2000, ETABS and SAFE", Berkeley, California, USA, 2010.

[37] K.J. Elwood, A.B. Matamoros, J.W. Wallace, D.E. Lehman, J.A. Heintz, A.D. Mitchell, M.A. Moore, M.T. Valley, L.N. Lowes, C.D. Comartin, and J.P. Moehle, Update to ASCE/SEI 41 Concrete Provisions, Earthquake Spectra, vol. 23, pp. 493-523, 2007.

[38] D.J. Kakaletsis, "Rotations of RC members of infilled frames at yielding and ultimate", The Open Construction and Building Technology Journal, vol. 6, pp. 50-62, 2012.
Received: December 02, 2013
Revised: December 19, 2013
Accepted: December 19, 2013
(C) Kirtas and Kakaletsis; Licensee Bentham Open.

This is an open access article licensed under the terms of the Creative Commons Attribution Non-Commercial License (http://creativecommons.org/licenses/by-nc/3.0/) which permits unrestricted, non-commercial use, distribution and reproduction in any medium, provided the work is properly cited. 